\title{
НЕОТЕКТОНИКА ЮЖНОЙ ЧАСТИ ХИБИНСКОГО МАССИВА: РЕЗУЛЬТАТЫ КОМПЛЕКСНОЙ ИНТЕРПРЕТАЦИИ ПРОТИВОРЕЧИВЫХ ЯВЛЕНИЙ
}

\author{
Жиров Д.В. ${ }^{1}$, Маринин А.В. ${ }^{2}$, Жирова А.М. ${ }^{1}$, Сим Л.А. ${ }^{2}$ \\ ${ }^{1}$ Геологический институт КНЦ РАН, Anamumbl, zhirov@geoksc.apatity.ru \\ ${ }^{2}$ ИФ3 РАН, Москва, marinin@yandex.ru
}

Хибинский щелочной плутон является крупнейшим в мире щелочным массивом, имеющим в плане форму овала размером примерно $44 \times 35$ км и площадью около 1330 км² $^{2}$ (рис. 1 ). Он образовался в ходе девонской тектоно-магматической активизации в северо-восточной части Фенноскандинавии [1]. Интрузив представляет собой конусообразный шток, переходящий в лополит, который мы классифицируем как структуру центрального (кольцевого) типа [8]. В строении Хибинского массива (XМ) контрастно выделяется кольцевой (конический) пояс - ийолит-уртитовая дуга (ИУД), с которой связаны месторождения мирового класса апатит-нефелиновых руд [13]. Большинство исследователей, в том числе и авторы, связывают образование этого пояса с древним коническим (центриклинальным) разломом, образовавшимся на одной из заключительных стадий щелочного магматизма. Вероятнее всего, на глубине и ближе к геометрическому центру плутона залегание этой структуры становится субвертикальным.

Древняя (синрудная и пострудная) тектоника обусловила формирование и последующие вещественные и морфологические преобразования основных рудных и геологических тел ИУД, а также разрывных структур, основными из которых являются крупные радиальные разломы и Главный разлом (ГР), представленный мощной зоной разрывных нарушений нескольких рангов соподчинения и с различной ориентацией в пространстве с общим падением вдоль залегания рудных тел (внутри и за пределами). Отличительной чертой всех элементов ГР служит шпреуштейнизация внутренней зоны нарушений и прилегающих пород мощностью от первых сантиметров до первых метров [12].

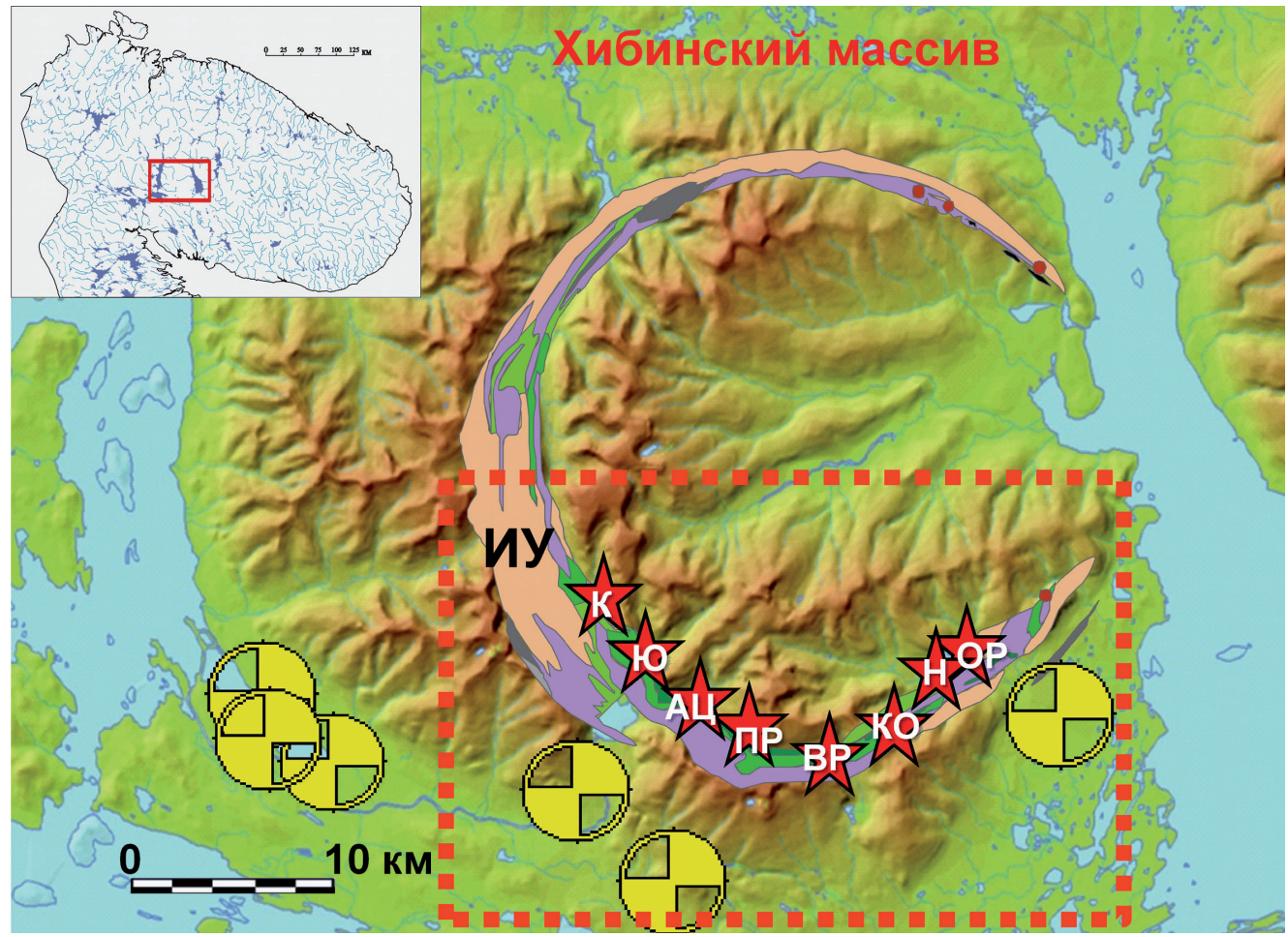

Рис. 1. Светотеневая карта рельефа Хибинского массива.

Красный пунктир - район исследований, ИУд - ийолит-уртитовая дуга (фоидолиты), красные звездочки апатит-нефелиновые месторождения: К - Кукисвумчорр, Ю - Юкспорр, АЦ - Апатитовый Цирк, ПР - Плато Расвумчорр, ВР - Восточный Расвумчорр, КО - Коашва, Н - Ньоркпахк, ОР - Олений Ручей); желтые круги - крупные техногенные объекты (обогатительные фабрики, хвостохранилища). 


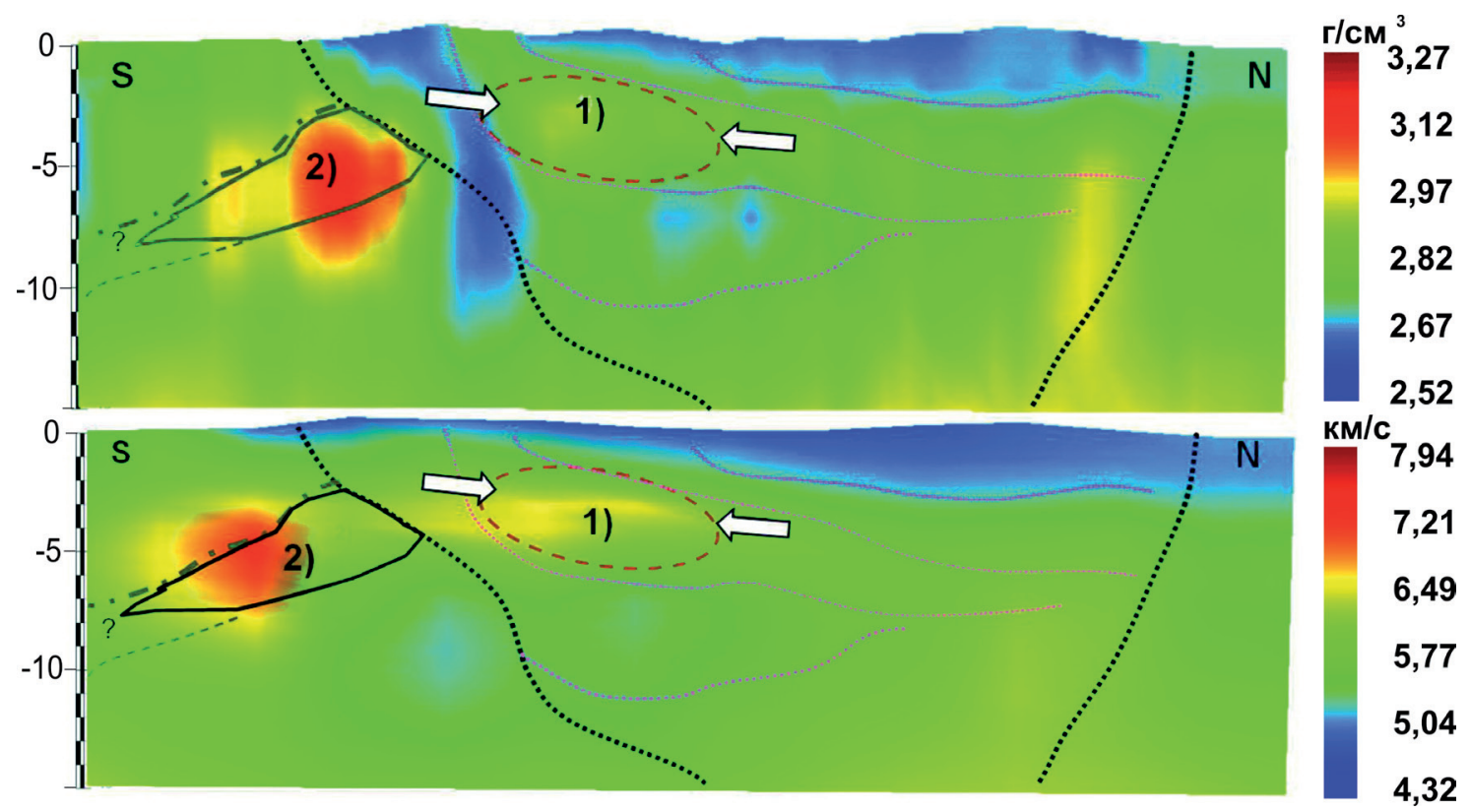

Рис. 2. Сечения ХМ в направлении Юг-Север через геометрический центр плотностной (a) и скоростной (b) моделей. Пунктирная линия точками - контуры ХМ; аномалия 1) - предполагаемая зона концентрации горизонтальных напряжений, аномалия 2) - предполагаемое слепое тело базит-гипербазитов.

Основными чертами неотектоники, по мнению большинства исследователей [3, 10, 11, 13 и др.], являются общая тенденция регионального поднятия с дифференциацией блоковых движений. Рельеф ХМ в целом сформирован как результат взаимодействия эндогенных и экзогенных факторов: долговременных восходящих блоковых движений, неоднократных оледенений и связанных с ними гляциоизостатических проявлений. Последним отдаётся превалирующая роль при интерпретации неотектоники [10, 11, 13].

К настоящему времени накоплена совокупность наблюдений и явлений, характеризующих современный тектонический режим ХМ как весьма сложный и противоречивый по многим показателям. В первую очередь это касается особенностей напряжённо-деформированного состояния (НДC). В ходе выполнения 3D сейсмоплотностного моделирования выявлено несколько локальных высокоскоростных и плотностных аномалий, одна из которых (№1 на рис. 2) расположена к югу от центральной части ХМ и имеет размер примерно $5 \times 10$ км [5]. Она начинается на глубине $1.5 \div 2.0$ км и отчётливо прослеживается примерно до глубины $3.5 \div 4.0$ км. Значения скорости в пределах аномалии достигает $6.8 \div 7.0$ км/с относительно фоновой скорости около 5.5 км/с. Существующие модельные представления о строении массива и данные глубокого бурения не позволяют привлечь для интерпретации этой аномалии только вещественный фактор, т.е. объяснить за счёт крупного геологического тела.

Другой характерной чертой НДС в районе разрабатываемых месторождений является субгоризонтальное положение главных сжимающих напряжений $\sigma 3$ с весьма высокими для приповерхностной части значениями (первые десятки МПа). Эти параметры получены в десятках инструментальных замерах «in situ» [9]. Как правило, $\sigma 3$ следуют вдоль простирания рудных тел согласно концентрической кольцевой структуре ИУД [15]. Эта закономерность вступает в противоречие с целым комплексом других показателей: кинематика молодых разрывных структур, механизмы реализации инструментально зафиксированных крупных сейсмодинамических событий [4], результаты геодезического мониторинга [15], а также реконструкции стресс состояний [7-8], которые определённо указывают на преобладание в районе ИУД южной части Хибин взбросовой кинематики относительных смещений с комплементарными сдвигами, что соответствует обстановке субгоризонтального сжатия в радиальном направлении. Ещё более осложняют общую картину результаты наших исследований [8] в краевой, приконтактовой части Хибин, где выявлены крупные сбросовые наруше- 

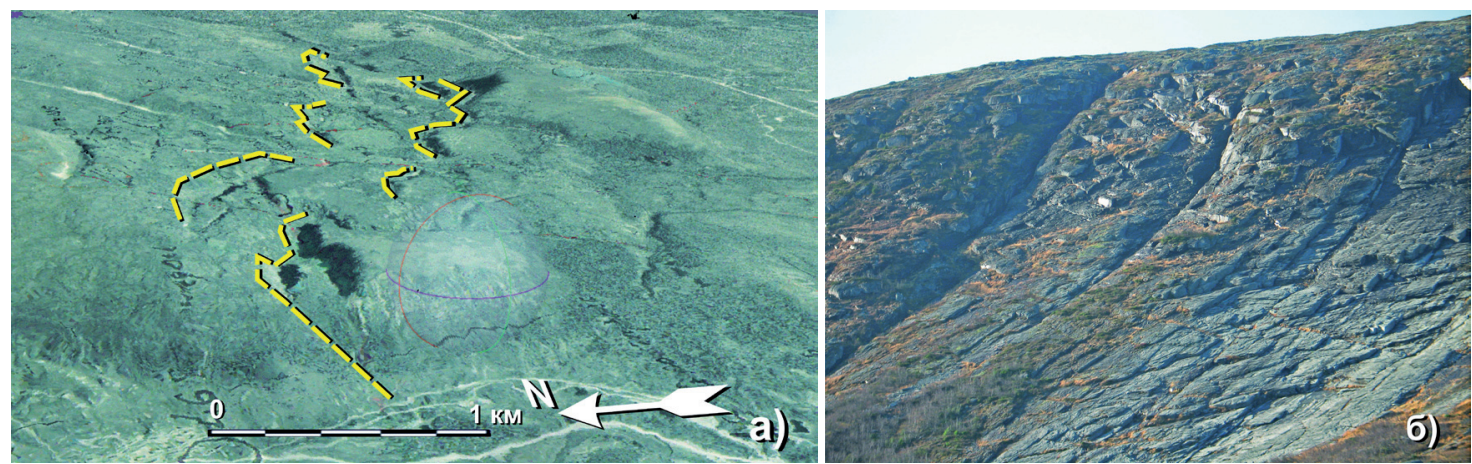

Рис. 3. Сбросы: а) скрин фотореалистической модели Хибин с выходом плоскостей сбросов (пунктир) на склоне г. Айкуайвенчорр; б) восточный склон г. Суолуайв, образованный поверхностью сброса, высота склона в кадре примерно 350-400 м.

ния (рис. 3), которые прослеживаются по всей южной половине и предполагаются для всего массива в целом. Кроме того, зафиксированы многочисленные проявления право- и левосторонних сдвигов в практическом большинстве площадок массовых замеров. Они также подтверждаются и прямыми геолого-структурными маркерами (положение складок, морфология рудных и позднемагматических тел и др.). Это принципиально новое отличие от всех ранее известных интерпретаций, которые в основном варьируют и отличаются друг от друга только в последовательности и знаке вертикальных и взбросо-сбросовых движений различных блоков [10-12]. Сдвиговую кинематику можно считать древней на основании её связи с проявлениями пликативной тектоники, однако для некоторых участков и блоков ХМ устанавливается унаследованный характер таких смещений вплоть до современных. Таким образом, перечисленные и многие другие явления и результаты исследований не могут быть уложены в рамки какой-либо упрощённой модели неотектоники.

Комплексный подход к интерпретации всей совокупности перечисленных явлений позволил авторам обосновать механизм современного тектонического развития Хибинского массива по типу реидного или протрузивного поднятия (прорывания вмещающих толщ) приповерхностной центральной части массива с одновременным смещением в радиальном направлении от центра к периферии за счёт разгрузки остаточных субгоризонтальных напряжений (рис. 4). Этот механизм объясняет несовместимую, на первый взгляд, фактографию за счёт дифференцированного и разнонаправленного движения различных частей массива. В результате опережающего поднятия ХМ единовременно формируются: в приконтактовой зоне на периферии интрузива - соскальзывания краевых частей с кинематикой сброса (обстановка субгоризонтального растяжения), взбросонадвиговые структуры в пределах ИУД (обстановка субгоризонтального сжатия), а также различные типы нарушений вблизи и внутри рудных тел вследствие модификации и усложнения структу-

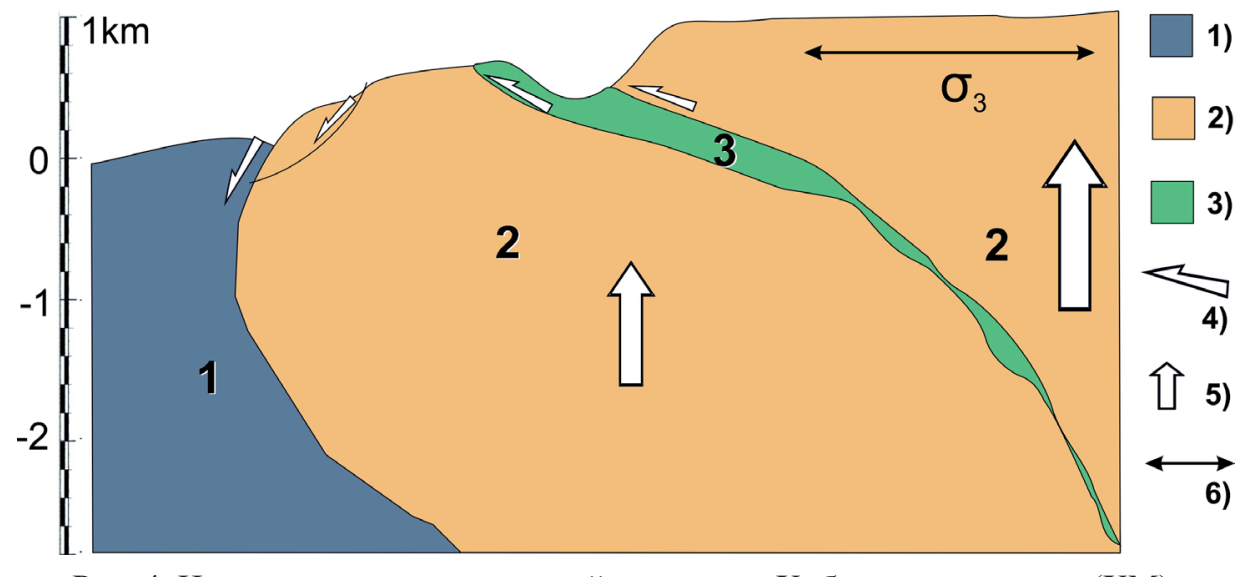

Рис. 4. Интерпретация современной тектоники Хибинского массива (ХМ).

1) - породы вмещающей рамы, 2) - ХМ, 3) - породы ийолит-уртитовой дуги, 4) - направление движения отдельных частей XM, 5) - реидное опережающее воздымание XМ и его интенсивность, 6) - направление главного сжимающего напряжения в приповерхностной части XМ. 
ры НДС. Благодаря различиям реологии вмещающих щелочных сиенитов, фоидолитов и богатых апатит-нефелиновых руд создаются предпосылки для концентрации напряжений и трансформации их направления действия вблизи и внутри рудных тел, что подтверждается интенсивным рассланцеванием и повышенной трещиноватостью этих зон.

Ключевым элементом предложенной модели служат высокие, преобладающие над литостатическими величины горизонтальных напряжений. Их источником могут служить различные явления и механизмы, начиная от гляциоизостазии, до механизма консервации повышенных остаточных субгоризонтальных напряжений в ходе быстрого поднятия [14]. Также может быть рассмотрен механизм транслирования повышенных напряжений с глубин к поверхности посредством структур двухосного сонаправленного поворота $[2,6]$.

Исследование выполнено в рамках научного проекта № 0231-2015-0013 «3D и 4D геологоструктурное моделирование в целях эффективного, рационального и безопасного освоения глубоких горизонтов стратегических полезных ископаемых». Изучение структуры двухосного сонаправленного поворота в пределах Ковдорского массива и оценка возможности выявления подобных структур в пределах Хибин поддержаны финансированием из средств гранта РФФИ 18-05-00590А.

\section{Литература}

1. Arzamastsev A.A., Mitrofanov F.P. Paleozoic plume-lithospheric processes in Northeastern Fennoscandia: evaluation of the composition of the parental mantle melts and magma generation conditions // Petrology. 2009. V. 17. № 3. P. 300-313.

2. Dmitry Zhirov New Type of Brittle Deformations: Two-Axial Turn Structure of Fractures in the Kovdor Carbonatite Intrusion (NW Russia) / Conference Proceedings SGEM-2017. Albena (Bulgaria), 2017. V. 17. Issue 11 Geology. Mineral Processing. P. 375-381.

3. Арманд А.Д. Развитие рельефа Хибин и Прихибинской равнины. М. 1964.

4. Виноградов Ю.А., Асминг В.Э., Кременецкая Е.О., Жиров Д.В. Современная сейсмичность на территории Мурманской области и ее проявление в горно-промышленных зонах. Новосибирск: СО РАН, ФТПРПИ. 1. 2016. С. 62-70.

5. Глазнев В.Н., Жирова А.М., Раевский А.Б. Новые данные о глубинном строении Хибинского и Ловозерского массивов, Кольский полуостров // ДАН. 2008. Т. 422. № 3. С. 391-393.

6. Жиров Д.В. Новый тип структурной упорядоченности разрывной тектоники в Ковдорском карбонатитфоскоритовом массиве (СВ Фенноскандинавского щита). Матер. L Тектонического совещания «Проблемы тектоники и геодинамики земной коры и мантии». 30.01-3.02 2018 г. ГИН и МГУ. Москва. М. 2018. T. 1. С. 181-185.

7. Жиров Д.В., Рыбин В.В., Шпаченко А.К. Эволюция хрупких деформаций массива пород Ньоркпахкского месторождения апатит-нефелиновых руд по результатам документации и анализа трещиноватости // Матер. конф. Тектонофизика и актуальные вопросы наук о Земле 13-17 октября 2008 г. ИФЗ РАН, Москва. М. 2008. T. 1. C. 124-127.

8. Жиров Д.В., Сим Л.А., Маринин А.В. Реконструкция палео стресс состояний в южной части Хибинского плутона (Восток Фенноскандинавского щита) // Тр. конф. «Актуальные проблемы динамической геологии при исследовании платформенных областей» МГУ 24-26 мая 2016. М: Изд-во «Перо». 2016. С. 39-44.

9. Козырев А.А., Семенова И.Э., Рыбин В.В., Аветисян И.М. Исследование напряженно-деформированного состояния массива пород численными методами на основе данных натурных измерений в окрестности крупной карьерной выемки // ГИАБ. 2011. № 11. С. 78-89.

10. Корсакова О.П., Колька В.В., Савченко С.Н. Блоковые структуры Кольского полуострова, их устойчивость в условиях природно-технических систем (на примере горных массивов Хибины и Ловозеро) // Вестник МГТУ. Т. 12. № 3. 2009. С. 478-491.

11. Николаева С.Б. Складчатые деформации в позднеплейстоценовых отложениях Хибин (центральная часть Кольского п-ова): морфология и генезис // Вестник МГТУ. 2014. Т. 17. № 2. С. 329-339.

12. Онохин Ф.М. Особенности структуры Хибинского массива и апатито-нефелиновых месторождений. Л.: Наука. 1975. 106 с.

13. Пожиленко В.И., Гавриленко Б.В., Жиров Д.В., Жабин С.В. Геология рудных районов Мурманской области. Апатиты: РИО КНЦ РАН, 2002. 359 с.

14. Ребецкий Ю.Л. О возможном механизме генерации в земной коре горизонтальных сжимающих напряжений // Докл. РАН. 2008. Т. 423. №4. С. 538-542.

15. Сейсмичность при горных работах. Под ред. Мельникова Н.Н. Кол. авт. Апатиты: Изд. КНЦ РАН. 2002. $325 \mathrm{c}$. 